\title{
An alternative technique to replace missing anterior tooth - A case report
}

\author{
Shruthadev Naik ${ }^{1 *}$, Purushothama Rangaswamy ${ }^{2}$, Samrat R. Magaravalli ${ }^{3}$, Sujith Ramachandra ${ }^{4}$, Kavitha \\ Govindappa $^{5}$
}

\author{
${ }^{1}$ Post Graduate, ${ }^{2}$ Professor, ${ }^{3} \mathrm{HOD},{ }^{4,5}$ Resident, Dept. of Conservative Dentistry and Endodontics, Sharavathi Dental College and Hospital, \\ Shivamogga, Karnataka, India \\ *Corresponding Author: Shruthadev Naik \\ Email: shruthadeva@gmail.com
}

\begin{abstract}
Missing anterior teeth is a significant social life problem for an individual. It is our duty, being a specialist in field of dentistry to replace and restore the missing anterior teeth. Various treatment options are available such as, conventional fixed partial denture, Maryland Bridge and implant supported prosthesis are considered for replacement of missing anterior teeth. The emergence of fiber reinforced composite has shown promising results because it is minimally invasive, less time consuming, cost effective and most importantly it restores the esthetics and functions of missing anterior teeth to its best way as immediately as possible.

This case report presents a clinical case of replacement of missing anterior tooth by restoring with direct fiber reinforced composite.
\end{abstract}

Keywords: Fiber reinforced composite, Ever Stick, Missing anterior teeth.

\section{Introduction}

Trauma to orofacial region is one of the most significant health care among the children and adolescents, apart from life threatening condition it can also result in fractured, displaced or loss of anterior teeth that can lead to a prominent negative effect on the functional, esthetic and psychological effects. ${ }^{1}$ Present day there is an increase demand for aesthetics by patients and as well as there is desire to reduce the cost of the treatment with best possible clinical outcome of the treatment in minimum clinical appointment. These reasons makes the clinical to pursue a new material and technique that ensures chair-side treatment in minimally invasive manner and aid in restoring integrity of missing anterior teeth. ${ }^{2}$

Numerous treatment options such as, removable partial dentures, porcelain fused metal bridge, Maryland Bridge and implants can be considered for treatment of traumatically missing permanent anterior teeth in young children and adolescent. But these treatment options are not usually indicated before the end of growth period because of the amount of tooth reduction, its invasiveness and considering its longevity all these options would have setback and limits its use. ${ }^{3}$

Fiber reinforced composite restorative procedure gives clinician enormous opportunity to overcome and solve many difficult situations in field of restorative dentistry. Two most important physical properties of fiber reinforced composite is its strength and stiffness which enhances its use compared to other restorative option. ${ }^{4}$ Fibers bind to resin present in the composite matrix through adhesive interface whereas nature of the fibers used and its geometry of arrangement aids in transferring the functional load from composite to fibers and it is distributed evenly onto the adjacent teeth. ${ }^{5}$

This clinical case report presents a case of replacement of missing anterior tooth with direct fiber reinforced composite.

\section{Case Report}

A 15 year old boy reported to Department of Conservative Dentistry and Endodontics with chief complaint of missing front tooth in the upper right side of the jaw region from 3 months back. Patient gives history of trauma while playing and fracture of upper front teeth. He also gives history of extraction of remaining fractured tooth fragment in private dental clinic on the same day of injury. On intraoral clinical examination maxillary right central incisor was absent \#11 and extraction socket was completely healed on clinical examination. There was no evidence of any root stump on radiographic examination of \#11. On extra oral examination there was no abnormalities detected. As the patient growth was not completed implant was not an ideal treatment option to be considered. So a minimally invasive conventional direct fiber reinforced composite resin bonded bridge was selected as a treatment option for prosthetic rehabilitation.

\section{Materials and Methods}

As a first step diagnostic impression of both upper and lower jaw was taken with additional silicone impression material (Zhermack). Under laboratory condition plaster models were made and wax mock up was fabricated on model in the region of missing \#11 for demonstration to patient and a palatal putty index template was made with additional silicone. The required length of fiber strip (GC ever Stick C\&B) was predetermined by using dental floss as template. A piece of $3 \mathrm{~mm}$ wide fiber strip was cut using scissors and kept away aside from light till used in the refrigerator. A slot preparation was done to a width of 2$3 \mathrm{~mm}$ and depth of $1 \mathrm{~mm}$ on palatal surface of \#21 and \#12 to receive the fiber strip. The palatal surface of \#21 and \#12 was etched with $37 \%$ phosphoric acid (3M ESPE) for 15seconds and bonding agent ( GC Solare universal bond) application was done and light cured (Bluephase, Ivoclar Vivadent) for 20seconds, following this the fiber strip was placed in the prepared palatal surface of \#21 and \#12 and 
bonded using composite resin ( GC Solare Sculpt). Now the putty index template and Mylar strip was placed on the palatal side to restore the palatal wall followed by chair side direct fabrication of composite pontic with natural layering technique was done with various shades of composite to match the tooth colour. Occlusion was checked and finally finishing and polishing was done with diamond burs (Mani) and disc (NMD and Shofu). This case was followed up for a period of 1year and the direct fiber reinforced composite bridge was found to be esthetically and functionally satisfactory.

\section{Discussion}

Harmony, beauty, individuality and naturalness are vital qualities of esthetics. ${ }^{6}$ Goal of dental and facial esthetics is dominated by maxillary anterior teeth. So the primary consideration for loss of any anterior teeth due to trauma or due to any other reason should be restored in harmony with natural appearance of face. ${ }^{7}$

Various therapeutic options should be taken into account for replacement of missing anterior teeth in young children and adolescent. Implant is considered as one of the viable treatment option for replacement of missing anterior teeth. ${ }^{8}$ Implant is not indicated before the age of 18years which marks the growth period of an individual. ${ }^{9}$ Another drawback of implant is its constraints on patients financial status, as implants are expensive treatment option. Before considering invasive conventional treatment option such as conventional fixed partial denture, Maryland bridge or implant therapy for replacement of missing anterior teeth, a versatile minimally invasive alternative and definitive long term treatment should be planned for missing anterior tooth within short duration of time.

Fiber reinforced composite (FRC) is one of the alternative treatment for replacing a missing anterior teeth. ${ }^{4}$ Vallipatu et.al demonstrated that survival rate of FRC bridge was $75 \%$ and even the repaired or rebonded FRC bridge showed survival rate of $93 \% .{ }^{10}$ With high survival rate and improved fiber technology FRC can be considered as potential treatment option to replace the other conventional mode of restoring the missing anterior teeth. ${ }^{11,12}$

The FRC material everStick C\&B (GC, America) which was used in the study has 4000 individually silanated E-glass fibers that are fully impregnated with resin. This fusion of fibers and resin forms the exceptionally strong esthetic friendly Interpenetrating Polymer Network (IPN). ${ }^{13}$ IPN technology ensures strong and consistent adhesion between the everStick fibers and over layered composite, they also have advantage of reactivation even after final polymerization. This reactivation is crucial for superior bonding when laboratory manufactured restoration are cemented to teeth and when FRC devices are remodeled or repaired. ${ }^{14}$ The everStick fibers have high tensile strength, flexural strength and good modulus of elasticity when compared to other polyethylene fibers which helps in evenly distribution of functional load on the fibers to abutment teeth. ${ }^{15}$ All this characteristics makes everStick fibers unique and ideal material of choice for replacement of missing anterior teeth.

A putty index was fabricated with help of wax up on diagnostic cast which acts as guide to establish adequate contact and contour of the teeth and reduce the chair side time necessary for the treatment. ${ }^{16}$ With help of putty index esthetics was best achieved using GC Solare Sculpt composite with various available shades to incrementally build dentin and enamel layers of tooth mimicking the natural shade of tooth with enhanced mechanical properties. This case was followed up for a period of 1 year and FRC Bridge was found to be stable without any clinical drawback.

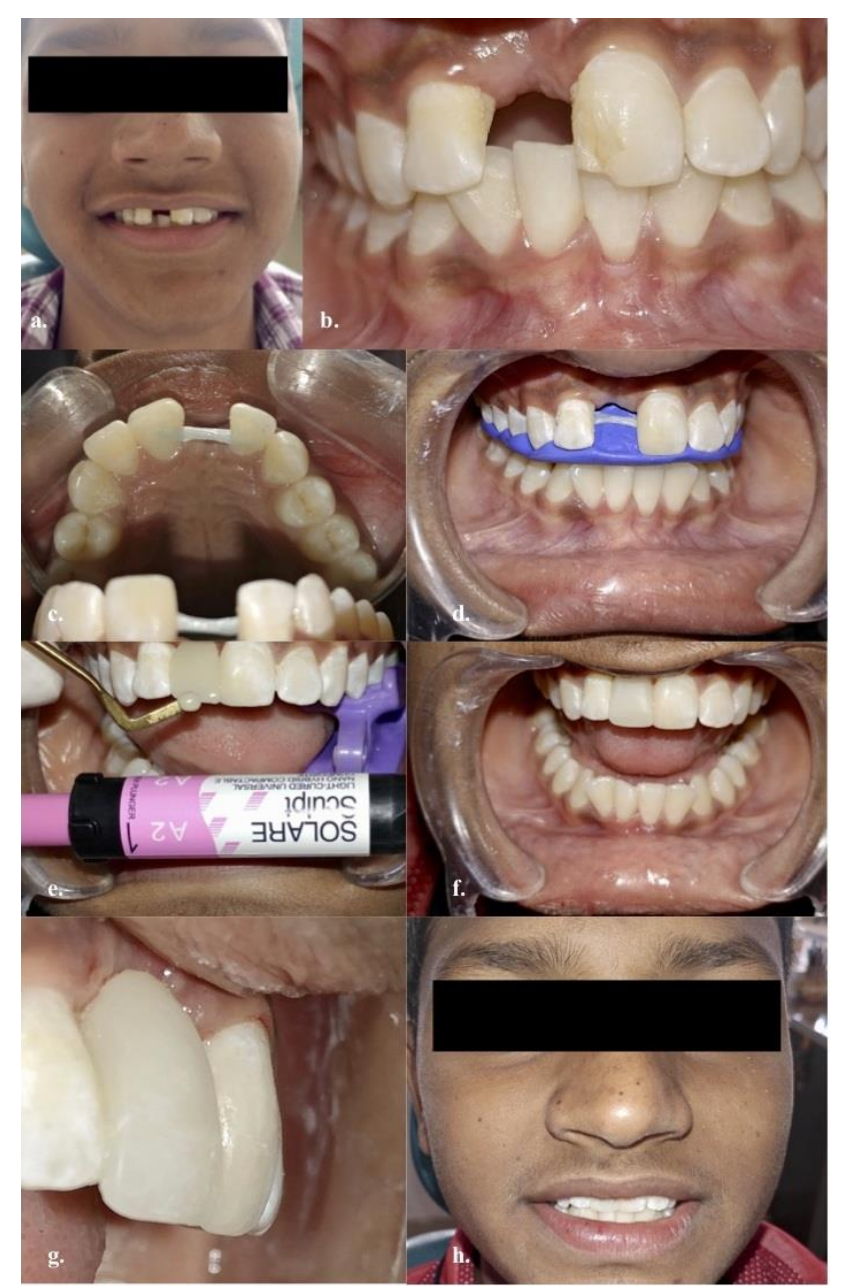

Fig. 1: a) Pre operative extra oral photograph, b) Pre operative intra oral photograph, c) everStick fiber cementation done after acid etching with $37 \%$ phosphoric acid and bonding agent application of \#21 and \#12, d) Putty index as guide for building palatal wall of \#11, e) Composite build of \#11, f) and g) frontal and lateral view of post operative photograph after finishing and polishing of fiber reinforced composite bridge irt \#11, h) Post operative extra oral photograph. 


\section{Conclusion}

Fiber reinforced composite bridge fabrication technique is absolute alternative and innovative treatment option for replacing missing anterior teeth. Using this technique it is possible to restore the tooth to its natural position with high quality of esthetics and function satisfying the criteria of minimally invasive approach.

\section{Source of funding}

None.

\section{Conflict of interest}

None.

\section{References}

1. Petersen PE. The World Oral Health Report 2003: continuous improvement of oral health in the 21 st century-the approach of the WHO Global Oral Health Programme. Comm Dent Oral Epidemiol 2003;31:3-24.

2. Garoushi S, Lassila L, Vallittu PK. Resin-bonded fiberreinforced composite for direct replacement of missing anterior teeth: A clinical report. Int J Dent 2011;2011.

3. Chafaie A, Portier R. Anterior fiber-reinforced composite resin bridge: a case report. Pediatric Dent 2004;26(6):530-4.

4. Butterworth C, Ellakwa AE, Shortall A. Fibre-reinforced composites in restorative dentistry. Dent Update 2003;30(6):300-6.

5. Kumar A, Tekriwal S, Rajkumar B, Gupta V, Rastogi R. A review on fibre reinforced composite resins. Ann Prosthod Restor Dent 2016;2(4):11-6.

6. Gomes VL, Gonçalves LC, Do Prado CJ, Junior IL, De Lima Lucas B. Correlation between facial measurements and the mesiodistal width of the maxillary anterior teeth. J Esthetic Restor Dent 2006;18(4):196-205.
7. Kumar MV, Ahila SC, Devi SS. The science of anterior teeth selection for a completely edentulous patient: a literature review. J Indian Prosthod Soc 2011;11(1):7-13.

8. Hanif A, Qureshi S, Sheikh Z, Rashid H. Complications in implant dentistry. Eur J Dent 201711(01):135-40.

9. Thilander B, Ödman J, Lekholm U. Orthodontic aspects of the use of oral implants in adolescents: a 10-year follow-up study. Eur J Orthod 2001;23(6):715-31.

10. Vallittu PK. Survival rates of resin-bonded, glass fiberreinforced composite fixed partial dentures with a mean follow-up of 42 months: A pilot study. J Prosthetic Dent 2004;91(3):241-6.

11. Jokstad A, Gökçe M, Hjortsjö C. A systematic review of the scientific documentation of fixed partial dentures made from fiber-reinforced polymer to replace missing teeth. Int $J$ Prosthod 2005;18(6).

12. van Heumen CCM, Kreulen CM, Creugers NHJ. Clinical studies of fiber-reinforced resin-bonded fixed partial dentures: a systematic review. Eur J Oral Sci 2009;117: 1-6.

13. Vallittu PK, Sevelius C. Resin-bonded, glass fiber-reinforced composite fixed partial dentures: a clinical study. J Prosth Dent 2000;84(4):413-8.

14. Vallittu PK. Interpenetrating polymer networks (IPNs) in dental polymers and composites. J Adhesion Sci Technol 2009;23(7-8):961-72.

15. Mangoush E, Säilynoja E, Prinssi R, Lassila L, Vallittu PK, Garoushi $\mathrm{S}$ et al. Comparative evaluation between glass and polyethylene fiber reinforced composites: A review of the current literature. J Clin Exp Dent 2017;9(12):e1408.

16. Maia LC. The reference guide: a step-by-step technique for restoration of fractured anterior permanent teeth. $J$ (Canadian Dent Ass) 2005;71(9):643-

How to cite: Naik S, Rangaswamy $P$, Magaravalli SR, Ramachandra S, Govindappa K. An alternative technique to replace missing anterior tooth - A case report. Indian $J$ Conserv Endod 2020;5(1):27-9. 